\title{
LICENCIAMENTO DE USINAS HIDRELÉTRICAS, RESERVATÓRIOS E ÁREAS DE PRESERVAÇÃO PERMANENTE
}

POWER PLANTS LICENSE, TANKS AND PERMANENT PRESERVATION AREAS

Pedro Curvello Saavedra Avzaradel ${ }^{1}$

\section{Resumo}

O presente trabalho tem como objeto analisar, concisamente, aspectos do regime jurídico ambiental aplicável a matriz hidroelétrica brasileira, incluindo os empreendimentos de grande porte e as chamadas pequenas centrais hidroelétricas. Dentro desse escopo, serão vistas, de forma panorâmica, as regras relativas ao licenciamento ambiental, focadas as chamadas áreas de preservação permanente, sobretudo após a edição do novo marco florestal - Lei 12.651/2012. Com base em dados oficiais, estudos e textos jurídicos específicos sobre o tema, serão debatidos os riscos para o setor hidrelétrico decorrentes da escassez de água e das alterações legislativas em questão. Pretende-se, sem a pretensão de esgotar o assunto, contribuir para importantes debates envolvendo nossas matrizes hídrica e energética, no contexto de um possível desenvolvimento sustentável.

Palavras chave: Aproveitamento hidrelétrico - Licenciamento Ambiental - Áreas de Preservação Permanente.

\begin{abstract}
This study aims to concisely analyze aspects of environmental legal regime related to the Brazilian hydroelectric matrix, including both large and small hydroelectric plants. Within this scope, it brings an overview of the rules concerning environmental permits, focused on permanent preservation areas (APPs), especially after the release of the new Brazilian Forest Code - Law 12,651/2012. Based on official data, on studies and specific legal texts on this issue, the paper discuss the risks to the hydroelectric sector resulting from water scarcity and the latest forest legislative amendments. Willing not to end, but rather to open this debate, it intends to contribute to important aspects involving brazilian's current water and energy crisis in the context of a still possible sustainable development.
\end{abstract}

Keywords: Hydroelectric Power Plants - Environmental Permits - Permanent preservation areas

\footnotetext{
${ }^{1}$ É Doutor em Direito da Cidade, graduado em Direito e mestre em Sociologia e Direito. É Professor do Curso de Direito do Polo Universitário de Volta Redonda da Universidade Federal Fluminense, onde lidera o Grupo de Estudos em Meio Ambiente e Direito. Integra o quadro permanente do Programa de Pós-Graduação em Direito Constitucional da mesma Universidade. É pesquisador do Grupo de Pesquisa Energias Renováveis, Descentralização e o papel dos Entes Federados da Universidade do Estado do Rio de Janeiro. Contato: pedroavzaradel@id.uff.br.
} 


\section{INTRODUÇÃO}

Podemos dizer que para quase tudo que se pretenda fazer hoje, necessitamos de energia. Desde as lâmpadas que iluminam casas e ruas, até o funcionamento de indústrias, eletrodomésticos, tudo depende de alguma forma de energia, sobretudo da elétrica.

Com o crescimento da população mundial ${ }^{2}$ e dos níveis de consumo (ainda que concentramos numa parcela pequena da população mundial), a demanda por energia no planeta, seja para fins comerciais e industriais, seja para fins residenciais, tem crescido de forma constante.

No caso Brasileiro, segundo dados do Ministério das Mimas e Energia, "entre 1970 e 1980 a demanda total de energia (Oferta Interna de Energia) aumenta 71,5\%, entre 1980 e 1990, 23,7\%, entre 1990 e 2000, 34,3\%, e, entre 2000 e 2005, 14,8\%"3.

Considerada estratégica para atender ao aumento da demanda por energia no mundo, a energia gerada a partir de potenciais hidroelétricos deve crescer de forma considerável no mundo nas próximas décadas.

De acordo com dados da Agência Internacional para Energias Renováveis (IRENA), as hidroelétricas geram menos de $20 \%$ da energia mundial e representam mais de $80 \%$ das energias renováveis. Os países que lideram o uso deste tipo de energia são China, Brasil, Canadá, Estados Unidos e Rússia ${ }^{4}$.

Segundo dados da IRENA, menos de $25 \%$ da capacidade mundial de geração está explorada, concentrado -se o restante nos continentes Africano, Asiático e Sul-americano. No que tange aos chamados projetos de pequena escala, apenas $5 \%$ do potencial estaria aproveitado. Ainda para a mesma agência internacional, os possíveis cenários projetam um aumento mundial entre 70 e 85 por cento na oferta deste tipo de energia entre os anos de 2007 e $2050 .{ }^{5}$

Desde a década de 80 do século XX, a geração elétrica a partir das águas possui destaque no Brasil. O sistema de geração de energia no Brasil está fortemente ancorado nas fontes

\footnotetext{
2 De acordo com dados de 2006 do Fundo das Nações Unidas para População, nos próximos 43 anos a população irá crescer em 2.5 bilhões de pessoas, número igual à população mundial em 1950, e atingir 9.2 bilhões em 2050. Esse crescimento tende a se concentrar em regiões pobres do mundo, especialmente nas áreas urbanas de países em desenvolvimento (Cf. as informações disponíveis em <http://www.unfpa.org/pds/trends.htm>. Acesso em 13 nov 2007).

${ }^{3}$ BRASIL. Ministério das Mimas e Energia. Matriz Energética Nacional 2030. Brasília: MME/EPE, 2007, p. 109.

4 International Renewable Energy Agency (IRENA). Renewable Energy Technologies: Cost analysis series. Volume 1. Power Sector. Issue 3/5, Hydropower. Abu Dhabi: 2012, p. 14.

${ }^{5}$ Ob. Cit., p. 15-16.
} 
hidroelétricas, que representam hoje, seguramente, mais de 70 por centro da nossa matriz elétrica e de 90 da energia elétrica consumida ${ }^{6}$.

Conforme dados do Ministério das Minas e Energia de 2007, temos cerca de 30 por cento do nosso potencial hidroelétrico em aproveitamento e mais de 400 instalações, sendo que pequena parcela dessas, menos de 30, concentra a maior parte da capacidade hidroelétrica instalada. Restaria, assim, um grande potencial (70\%) inexplorado. ${ }^{7}$

Levando-se em conta os cenários de crescimento da economia e aumento da demanda por energia para fins residenciais e industriais, existe um planejamento por parte do Estado Brasileiro para que se aumente a oferta interna de energia elétrica. E neste ponto, novamente, existe o foco, a prioridade conferida à geração hidroelétrica, com várias usinas em construção e aproveitamentos energéticos em fase de estudos. Contudo, tal não ocorre sem alguns importantes questionamentos.

De um lado, a geração de energia hidroelétrica não depende exclusivamente de fatores topográficos (ex. relevo existência de quedas d'água) e tecnológicos (ex. modelos de turbinas geradoras e reservatórios), mas sobretudo do insumo água. Este vital insumo depende não apenas do regime das chuvas, mas de sua correta gestão - que inclui a manutenção dos processos ecológicos essenciais ao ciclo de renovação da água.

Ocorre que, atualmente, existem mudanças em curso e projeções de médio prazo no regime das chuvas em razão das mudanças climáticas globais. Conforme o Painel Intergovernamental das Nações Unidas sobre Mudanças Climáticas (IPCC), serão intensificados os chamados extremos climáticos, o que pode significar períodos maiores de estiagem e chuvas concentradas em curtos períodos ${ }^{8}$.

Certamente, as mudanças na disposição da água no planeta e na forma como ocorrerão as chuvas representam sérios riscos para várias instalações hidroelétricas em operação, em construção ou planejadas para operar.

Soma-se à questão climática a péssima gestão dos recursos hídricos no Brasil e a interferência humana negativa no ciclo de renovação da água. Sobre a questão da gestão, parece esclarecedor (e, ao mesmo tempo, estarrecedor), que dados oficiais referentes a 2013 reconheçam

\footnotetext{
${ }^{6}$ Conforme dados de 2007 do Ministério de Minas e Energia, "essas usinas correspondem a 75\% da potência instalada no país e geraram, em 2005, 93\% da energia elétrica requerida no Sistema Interligado Nacional SIN" (ob. cit., p. 28).

${ }^{7}$ Idem. Ibidem., p. 23-25.

8 IPCC. Mudança do Clima 2007: A Base das Ciências Físicas Contribuição do Grupo de Trabalho I ao Quarto Relatório de Avaliação do Painel Intergovernamental sobre Mudança do Clima. Genebra, 2007.
} 
uma perda real média nacional de $37 \%$ por cento nos sistemas de abastecimento de água e que apenas 39\% do esgoto gerado possui tratamento 9 .

Por fim, outro ponto crucial é que, de forma geral, as áreas de recarga dos aquíferos, o entorno de nascentes e as margens de rios carecem de políticas públicas de proteção, apesar de todo o aparato legal ambiental existente.

Para citarmos um exemplo, resta em São Paulo pouco mais de $20 \%$ da vegetação nativa protetora de mananciais ${ }^{10}$. A partir de dados do 'Altas dos Remanescentes Florestais da Mata Atlântica 2012-2013', o instituto SOS Mata Atlântica, coautor do estudo, constatou que:

A cobertura florestal nativa na bacia hidrográfica e nos mananciais que compõem o Sistema Cantareira, centro da crise no abastecimento de água que assola São Paulo, está pior do que se imaginava. Hoje, restam apenas $488 \mathrm{~km} 2(21,5 \%)$ de vegetação nativa na bacia hidrográfica e nos $2.270 \mathrm{~km} 2$ do conjunto de seis represas que formam o Sistema Cantareira.

O levantamento avaliou também os $5.082 \mathrm{~km}$ de rios que formam o sistema. Desse total, apenas 23,5\% (1.196 km) contam com vegetação nativa em área superior a um hectare em seu entorno. Outros 76,5\% (3.886 km) estão sem matas ciliares, em áreas alteradas, ocupadas por pastagens, agricultura e silvicultura, entre outros usos ${ }^{11}$.

Recentemente, em razão das escassez de água - que, como visto, não se resume às chuvas, algumas Usinas Hidroelétricas tiveram de parar ou reduzir sua operação ${ }^{12}$. No primeiro mês de 2015, em alguns reservatórios como Santa Branca ${ }^{13}$ e Paraibuna ${ }^{14}$ (inseridos na Bacia do Rio Paraíba do Sul), o nível de armazenamento de água ficou abaixo do mínimo operacional, passando a ser utilizada e chamada reserva técnica (volume morto) para fins de abastecimento das regiões metropolitanas.

\footnotetext{
9 BRASIL. Ministério das Cidades. Secretaria Nacional de Saneamento Ambiental. Sistema Nacional de Informações sobre Saneamento: Diagnóstico dos Serviços de Água e Esgotos - 2013. - Brasília: MCIDADES.SNSA, 2014, p. 1. Trata-se da média, cabendo destacar que vários prestadores de serviço de abastecimento no país apresentam perdas superiores a 50\% (Idem. Ibidem, p. 30).

10 HIROTA, Marcia. Por que desmatar $79 \%$ da área de mananciais secou São Paulo. Disponível em http://www.sosma.org.br/101149/por-que-desmatar-79-da-area-de-mananciais-secou-saopaulo/\#sthash.jOsvXhWt.dpuf. Acesso em 28 jan. 2015.

11 Idem. Ibidem.

12 Vide NITAHAR, Akemi. Nível baixo dos reservatórios leva segunda hidrelétrica a parar. Disponível em http://agenciabrasil.ebc.com.br/geral/noticia/2015-01/nivel-baixo-dos-reservatorios-leva-segundahidreletrica-parar. Acesso em 26 jan. 2015.

${ }^{13}$ AGÊNCIA NACIONAL DE ÁGUA (ANA). Reserva Técnica começa a ser usada no Santa Branca, no Paraíba do Sul. Disponível em www2.ana.gov.br/Paginas/imprensa/noticia.aspx?id_noticia=12650. Acesso em 28 jan. 2015.

14 Idem. Reservatório Paraíbuna, no Paraíba do Sul, começa a usar reserva técnica. Disponível em http://www2.ana.gov.br/Paginas/imprensa/noticia.aspx?id_noticia=12649. Acesso em 28 jan. 2015.
} 
Embora se saiba que o uso dos recursos hídricos por instalações hidroelétricas é nãoconsuntivo - não altera significativamente a quantidade disponível do recurso, compete com outros, o que pode gerar conflitos no futuro próximo ${ }^{15}$.

Nesse contexto de escassez - sem perspectivas de cenários mais otimistas a médio prazo, mostra-se necessário repensar os usos da água pelos setores produtivos. Isto porque todo produto possui alguma quantidade de água embutida (utilizada) em seu processo de fabricação e distribuição $0^{16}$ - a chamada água virtual ${ }^{17}$.

Nas últimas décadas, o Brasil vem se consolidando como grande exportador indireto de água, considerando, principalmente, o comércio de grãos, minérios e carne, produtos que demandam grandes quantidades de água nas etapas de fabricação e beneficiamento.

Segundo dados da UNESCO de 2011, o Brasil é o quarto maior exportador de água virtual do mundo, transferindo, indiretamente, para outros países, 112 trilhões de litros desse recurso por ano ${ }^{18}$.

De outro lado, as usinas hidroelétricas, embora sejam consideradas como fontes renováveis e limpas de energia, enfrentam hodiernamente sérios questionamentos socioambientais.

Tradicional e majoritariamente, defini-se a energia obtida a partir da água como renovável. Neste aspecto, Daniel Botkin e Eduard Keller fazem a seguinte observação:

A energia hidráulica é uma energia limpa; ela não requer nenhuma queima de combustível, não polui a atmosfera, não produz resíduos radioativos ou outros, e é eficiente. No entanto, há preços ambientais a pagar:

1. Grandes barragens e reservatórios inundam extensas áreas de terra que poderiam ter outros usos. Por exemplo, cidades e terras agricultáveis podem ser perdidas.

2. Barragens bloqueiam a migração de alguns peixes, como salmão, e as represas e reservatórios alteram intensamente os habitats de muitas espécies de peixes.

\footnotetext{
${ }^{15}$ Vale lembrar que a Lei 9.433/1997, que aprova a Política Nacional de Recursos Hídricos prioriza o uso múltiplo das águas, com atenção especial ao uso por seres humanos e para a dessedentação de animais.

${ }^{16}$ Conforme CARMO, Roberto Luiz do Et Al, "em sua essência, água virtual diz respeito ao comércio indireto da água que está embutida em certos produtos, especialmente as commodities agrícolas, enquanto matéria prima intrínseca desses produtos. Ou seja, toda água envolvida no processo produtivo de qualquer bem industrial ou agrícola passa a ser denominada água virtual" (CARMO, Roberto Luiz do; Et. Al. Água virtual, escassez e gestão: O Brasil como grande "exportador" de água, p. 84. In: Ambiente \& Sociedade. Campinas v. X, n. 2, p. 83-96, jul.-dez. 2007).

${ }^{17}$ CARLI, Ana Alice de. A água e seus instrumentos de efetividade. Campinas: Millennium Editora, 2013, p. 73.

18 MEKONNEN, M.M; HOEKSTRA, A.Y. (2011) National water footprint accounts: the green, blue and grey water footprint of production and consumption, Value of Water Research Report Series $n$. 50. Delft (Netherlands): UNESCO-IHE, 2011, p. 20.
} 
3. Barragens armazenam sedimentos que, de outra forma, chegariam ao mar e eventualmente reconstituiriam a areia nas praias.

4. Por diversas razões, muitas pessoas não querem transformar rios selvagens em uma série de $\operatorname{lagos}^{19}$

Embora seja tratada como fonte renovável e limpa pelo Governo Brasileiro e pela IRENA, o fato é que a energia a partir de plantas hidroelétricas vem sofrendo críticas contundentes, seja em relação à geração de gases de efeito estufa (p. ex. a produção de gás metano), seja em relação aos impactos socioambientais (p. ex. o deslocamento de comunidades e a transformação abrupta de pequenas cidades).

A emissão de gases de efeito estufa decorre da composição das matérias (ex. árvores) nas áreas alagadas para criar os reservatórios. O principal gás emitido é o metano, várias vezes mais potente do que o carbono na retenção de calor e, logo, na contribuição para o efeito estufa ${ }^{20}$. A limpeza das áreas a serem alagadas aparece como uma medida mitigatória importante, embora custosa para os empreendedores.

De acordo com o estudo específico elaborado em 2006 sobre as emissões dos reservatórios hidrelétricos ${ }^{21}$.

A intensidade de emissão de gases em um reservatório não é invariante no tempo. Há flutuações com períodos de duração irregular. No entanto, a variação é modulada por um conjunto de influências, sendo as principais: a temperatura, o regime de ventos, a insolação, os parâmetros físico-químicos da água e a composição da biosfera ${ }^{22}$.

Para Salvador Pueyo e Philip M. Fearnside, as estimativas oficiais do governo brasileiro sobre as emissões de gás metano nos reservatórios existentes estão subestimadas ${ }^{23}$.

Contudo, são os impactos sociais aqueles que geram as maiores controvérsias. deslocamento de populações locais e a atração de milhares de trabalhadores e prestadores de serviços frequentemente fomentam mudanças radicais (ex. ciclos de prostituição, especulação

\footnotetext{
${ }^{19}$ BOTKIN, Daniel B; KELLER, Eduard A. Ciência ambiental: terra, um planeta vivo. Rio de Janeiro: LTC, 2011, p. 390-391.

20 Os cientistas divergem sobre a relação entre os potenciais danosos dos gases metano e carbônico, havendo os que sustentam ser o metano 16 vezes mais potente e os que sustentam ser o 21 vezes mais potente.

${ }^{21}$ BRASIL. Ministério da Ciência e Tecnologia. Primeiro Inventário Brasileiro de Emissões Antrópicas de Gases de Efeito Estufa. Relatórios de referência: emissões de dióxido de carbono e de metano pelos reservatórios hidrelétricos brasileiros. Brasília: 2006.

22 Idem. Ibidem, p. 72.

23 FEARNSIDE, Philip M.; PUEYO, Salvador. Emissões de gases de efeito estufa em reservatórios de hidroelétricas: implicações de uma lei de potencia. Oecologia Australis, 2011, p. 210. Segundo os autores, a quantidade de gás metano emitida seria três vezes maior do que a oficialmente informada pelo governo Brasileiro.
} 
imobiliária, deslocamentos de população, etc.) em cidades geralmente sem o planejamento e a estrutura necessários para a demanda por serviços públicos e equipamentos de uso coletivo.

Um ponto no qual convergem as preocupações com a iminente escassez de recursos hídricos e com as mudanças climáticas diz respeito a manutenção das chamadas áreas de preservação permanente, espaços especialmente protegidos e que, em regra, se destinam à manutenção de locais com a vegetação nativa, autênticos estoques de carbono, sendo excepcional e restrita a intervenção nos mesmos.

Em termos gerais e iniciais, a legislação atual, comparada com a anterior, traz um quadro de maior permissividade na intervenção, supressão, manutenção e recuperação desses espaços, havendo alguns dispositivos voltados de forma específica para os empreendimentos de geração de energia a partir do aproveitamento de potenciais hidráulicos, os quais serão analisados adiante.

\section{O LICENCIAMENTO DE USINAS E PEQUENAS CENTRAIS HIDROELÉTRICAS}

Tal é a importância da energia hidráulica em nosso país que a mesma possui previsão constitucional. Nos termos da Constituição de $1998^{24}$, os potenciais hidroelétricos são propriedade da União, a quem cabe explora-los, diretamente ou por meio de concessões. Em terras indígenas, o exige-se, adicionalmente às autorizações e licenças necessárias, a devida oitiva das comunidades e a autorização do Congresso Nacional ${ }^{25}$.

De forma sintética, podemos dizer que a construção e a operação de uma usina hidroelétrica ou de uma pequena central hidroelétrica interliga, pelo menos, três microssistemas jurídicos.

Primeiramente, depende o aproveitamento energético do aval do Sistema Nacional de Recursos Hídricos (SNRH) e da necessária outorga para o uso do água - fato que enseja a cobrança por tal uso ${ }^{26}$. No que se refere à regulação setorial (concessão para exploração), deve o empreendimento adequar-se às normas técnicas expedidas pela Agência Nacional de Energia

\footnotetext{
${ }^{24}$ BRASIL. Constituição da República Federativa do Brasil, de 5 de outubro de 1988. Brasília: 1988.

${ }^{25}$ Idem. Ibidem., artigos 20, inc. VIII e $\S 10 ; 21$, inc. XII, 'b'; 23, inc. XI; 49, inc. XVI; 176;

${ }^{26}$ BRASIL. Lei 9.433, de 8 de janeiro de 1997. Institui a Política Nacional de Recursos Hídricos, cria o Sistema Nacional de Gerenciamento de Recursos Hídricos. Brasília: 1997. Vide os artigos 12, inc. IV, 20 e 35, inc. III. No Estado do Rio de Janeiro, confira-se a respectiva Política Estadual, nos artigos 22. inc. IV e § 30; 27, § 10 e 45, IV (ESTADO DO RIO DE JANEIRO. Lei 3.239, de 2 de agosto de 1997. Institui a Política Estadual de Recursos Hídricos, cria o Sistema Estadual de Gerenciamento de Recursos Hídricos. Rio de Janeiro: 1999.
} 
Elétrica (ANEEL) ${ }^{27}$. Por fim, igualmente, depende do licenciamento ambiental e da adequação à normas e padrões ambientais aplicáveis.

Pode-se dizer que o licenciamento ambiental é um instrumento de controle prévio de atividades, com base em leis, regulamentos e normas técnicas, cujo objetivo é compatibilizar o empreendimento com a tutela do meio ambiente equilibrado. Traduz o preventivo exercício do Poder de Polícia Administrativa, concretizando importantes princípios do Direito Ambiental como o da prevenção, o da precaução e do poluidor-pagador.

Nos termos do artigo 2o, inciso I, da Lei Complementar 140/2011, trata-se do:

Procedimento administrativo destinado a licenciar atividades ou empreendimentos utilizadores de recursos ambientais, efetiva ou potencialmente poluidores ou capazes, sob qualquer forma, de causar degradação ambiental ${ }^{28}$.

Conforme o Banco Mundial, em estudo de 2008, "o licenciamento ambiental de empreendimentos hidrelétricos no Brasil é percebido como um grande obstáculo, resultando em atrasos no desenvolvimento dos empreendimentos. Essa condição resulta da parcial falta de sincronia entre os marcos regulatórios dos setores ambiental e elétrico"29.

De acordo com a clássica trilogia consagrada na Resolução n. 237/1997 do Conselho Nacional do Meio Ambiente (CONAMA), o licenciamento divide-se, em regra, nas fases: a preliminar ou prévia; a de instalação ou de implementação; a de operação.

$\mathrm{Na}$ fase preliminar ou prévia, são analisados aspectos relativos à localização do empreendimento e à sua viabilidade ambiental. Nesse ponto são apresentados aos órgão ambiental estudos de viabilidade e, sendo o caso, o Estudo Prévio de Impacto Ambiental e seu relatório (EIA/RIMA) $)^{30}$.

\footnotetext{
27 BRASIL. Lei 9.427, de 24 de setembro de 1996. Institui a Agência Nacional de Energia Elétrica - ANEEL, disciplina o regime das concessões de serviços públicos de energia elétrica e dá outras providências. Brasília: 1996. Vide os artigos 24,26 e 28 , dentre outros.

${ }^{28}$ BRASIL. Lei Complementar 140, de 8 de dezembro de 2011. Regulamenta o parágrafo único do artigo 23 da Constituição Federal. Brasília: 2011.

${ }^{29}$ BANCO MUNDIAL. Licenciamento Ambiental de Empreendimentos Hidrelétricos no Brasil: uma Contribuição para o Debate. Volume II: relatório principal. Brasília: 2008. p. 2011.

${ }^{30}$ Nos termos do artigo 2o, inciso VII, da Resolução n. 1, de 23 de Janeiro de 1986, dependem da realização do EIA/RIMA "obras hidráulicas para exploração de recursos hídricos, tais como: barragem para fins hidrelétricos, acima de $10 \mathrm{MW}$, de saneamento ou de irrigação, abertura de canais para navegação, drenagem e irrigação, retificação de cursos d'água, abertura de barras e embocaduras, transposição de bacias, diques" (BRASIL. Conselho Nacional do Meio Ambiente. Resolução n. 1, de 23 de Janeiro de 1986. Dispõe sobre critérios básicos e diretrizes gerais para a avaliação de impacto ambiental. Brasília: 1986).
} 
É nesta fase que se verifica a disponibilidade de água necessária para o empreendimento na bacia hidrográfica, o que deve ser atestado pelo $\mathrm{SNRH}^{31}$, bem como o melhor lugar na extensão do rio para localizar o reservatório e a usina ou pequena central hidrelétrica.

$\mathrm{Na}$ fase de implementação são avaliados impactos da construção e as respectivas medidas de controle, sendo o momento ideal de apresentação do projeto executivo da obra. Somente após a obtenção dessa licença que pode ser iniciada a implementação do empreendimento.

Já na fase final do licenciamento são analisados os impactos e medidas de mitigação relativos à operação da atividade, que somente poderá ocorrer após a expedição da respectiva Licença de Operação.

O CONAMA expediu algumas normas específicas para o licenciamento de hidrelétricas. Neste ponto, destacamos, sem a pretensão de esgotar o assunto, as Resoluções n. 06/1987 ${ }^{32}$ e $279 / 2001^{33}$.

A primeira estabelece os documentos e estudos necessários para cada fase do licenciamento, bem como a relação entre cada uma delas e as etapas do empreendimento ${ }^{34}$. Já a segunda estabelece um procedimento simplificado para empreendimentos hidrelétricos de menor potencial de impacto ${ }^{35}$.

Dentro do licenciamento de empreendimentos hidrelétricos, um ponto sensível consiste em identificar (em regra na fase prévia) e observar (nas restantes) a existência de espaços territoriais especialmente protegidos, tais como as áreas de preservação permanente, que passamos a abordar em seguida.

\footnotetext{
${ }^{31}$ Veja-se, a título de exemplo, a Resolução n. 21, de 19 de novembro de 2010 da Agência Nacional de Águas (ANA), que declara reservada à Agência Nacional de Energia Elétrica (ANEEL), nos termos do texto, a vazão necessária para o aproveitamento hidrelétrico no Rio Teles Pires.

32 BRASIL. Conselho Nacional do Meio Ambiente. Resolução n. 6, de 16 de setembro de 1987. Dispõe sobre o licenciamento ambiental de obras do setor de geração de energia elétrica. Brasília: 1987.

${ }_{33}$ BRASIL. Conselho Nacional do Meio Ambiente. Resolução n. 279, de 27 de junho de 2001. Estabelece procedimentos para o licenciamento ambiental simplificado de empreendimentos elétricos com pequeno potencial de impacto ambiental. Brasília: 2001.

${ }^{34}$ Por exemplo, nos termos do artigo 4o da Resolução n. 6/1987, "na hipótese dos empreendimentos de aproveitamento hidroelétrico, respeitadas as peculiaridades de cada caso, a Licença Prévia (LP) deverá ser requerida no início do estudo de viabilidade da Usina; a Licença de Instalação (LI) deverá ser obtida antes da realização da Licitação para construção do empreendimento e a Licença de Operação (LO) deverá ser obtida antes do fechamento da barragem" (Idem. Ob. Cit).

${ }^{35}$ Nesses casos, a avaliação acerca do pequeno potencial de impacto é feita a partir do Relatório Ambiental Simplificado - que contém informações sobre os impactos gerados na operação e na implementação, além de um diagnóstico ambiental da área em que se pretende locar o empreendimento. Confirmado o pequeno potencial poluidor pelo órgão ou autarquia responsável pelo licenciamento, não será exigido o EIA/RIMA e nem haverá audiência pública, mas sim uma reunião técnica informativa (Idem. Ob. Cit., arts. 30, 40 e 80).
} 


\section{ÁREAS DE PRESERVAÇÃO PERMANENTE E GERAÇÃO DE ENERGIA}

Podemos dizer que o instituto das áreas de preservação permanente (APPs), embora possua algumas aproximações com o antecessor instituto das florestas protetoras (previstas no Código de 1934) ${ }^{36}$, surge a partir da Lei 4.771/1965 como o espaço cuja preservação é constante, permanente, com as ressalvadas previstas no texto legal.

Conceituou-se legalmente o instituto na vigência do Código de 1965, por meio da MP 1.956-50/2000 ${ }^{37}$, seguida, em linhas gerais, pelo artigo 3o, inciso II, da Lei 12.651/2012, que revogou o código anterior a citada medida provisória. Eis o conceito legal em vigor:

Área protegida, coberta ou não por vegetação nativa, com a função ambiental de preservar os recursos hídricos, a paisagem, a estabilidade geológica e a biodiversidade, facilitar o fluxo gênico de fauna e flora, proteger o solo e assegurar o bem-estar das populações humanas ${ }^{38}$.

Ao comentar o instituto, ainda com base no Código Florestal de 1965, Paulo Afonso Leme Machado destaca a razão de ser do termo 'área':

O espaço territorial em que a floresta ou vegetação devem estar presentes. Se a floresta aí não estiver, ela deve ser plantada. A ideia da permanência não está vinculada só à floresta, mas também ao solo, no qual ela está ou deve ser inserida, e à fauna (micro ou macro). Se a floresta perecer ou for retirada, nem por isso a área perderá sua normal vocação florestal.

A vegetação, nativa ou não, e a própria área são objeto da preservação não só por si mesmas, mas pelas funções protetoras das águas, do solo, da biodiversidade (aí compreendido o fluxo gênico de fauna e flora), da paisagem e do ser humano. A área de preservação permanente -

\footnotetext{
${ }^{36}$ AVZARADEL, VIde Pedro Curvello Saavedra . Das Florestas Protetoras às Áreas de Preservação Permanente: considerações sobre os retrocessos na legislação florestal atual. In: XXII Encontro Nacional do CONPEDI / UNICURITIBA, 2013, Curitiba. Direito Ambiental II XXII Encontro Nacional do CONPEDI/UNICURITIBA. Florianópolis: FUNJAB, 2013. p. 164-184.

${ }^{37}$ Idem. Medida Provisória n. 1.956-50, de 26 de maio de 2000. Altera os arts. 1ㅇ, 4ํ, 14, 16 e 44, e acresce dispositivos à Lei no 4.771, de 15 de setembro de 1965, que institui o Código Florestal, bem como altera o art. 10 da Lei no 9.393, de 19 de dezembro de 1996, que dispõe sobre o Imposto sobre a Propriedade Territorial Rural - ITR, e dá outras providências. Brasília: 2000. Disponível em www.senado.gov.br. Acesso em 03 ago 2012. As APP são conceituadas por este ato normativo como "área protegida nos termos dos arts. 20 e 3o desta Lei [4.771/1965], coberta ou não por vegetação nativa, com a função ambiental de preservar os recursos hídricos, a paisagem, a estabilidade geológica, a biodiversidade, o fluxo gênio de fauna e flora, proteger o solo e assegurar o bem estar das populações humanas"(Idem. Ibidem).

38 BRASIL. Lei n. 12.651, de 25 de maio de 2012. Dispõe sobre a proteção da vegetação nativa; altera as Leis nos 6.938, de 31 de agosto de 1981, 9.393, de 19 de dezembro de 1996, e 11.428, de 22 de dezembro de 2006; revoga as Leis nos 4.771, de 15 de setembro de 1965, e 7.754, de 14 de abril de 1989, e a Medida Provisória n 2.166-67, de 24 de agosto de 2001; e dá outras providências. Brasília: 2012.
} 
APP não é um favor da lei, é um ato de inteligência social e de fácil adaptação às condições ambientais ${ }^{39}$.

Dentre as várias razões que justificam este instituto, pode-se destacar o bem estar e a segurança dos seres vivos. O fato de não se poder ocupar e construir em áreas de preservação permanente representa uma forma de diminuir os riscos de perdas materiais e de vidas em razão de extremos climáticos.

Outro argumento é que as APPs são fundamentais para garantia do ciclo da água, desde a infiltração no solo até a proteção de nascentes, cursos d'água, lagos, lagoas e reservatórios. Igualmente, contribuem para controlar processos naturais de erosão e assoreamento nesses locais.

Existem áreas de preservação permanente cuja observância decorre diretamente da lei e outras que podem ser criadas pelo Poder Público, conforme os artigos 4 o e 6 o da Lei 12.651/2012. Em seu artigo 50, o aludido diploma traz regras específicas para reservatórios d'água artificiais destinados a produção de energia ou ao serviço público de abastecimento de água.

Trata-se de APP pelo simples efeito da lei, mas que, diferente de outras APPs previstas no artigo anterior da mesma lei, configura-se concretamente pela Administração Pública, observados os limites legais. Por se tratar de artigo e regime específicos, entendemos que não se aplicam a esses reservatórios os parágrafos 10 e 40 do artigo anterior.

Vale lembrar o Código de 1965 (Lei 4.771/65) não trazia limites quantificados ou metragens expressas, remetendo a questão à disciplina do CONAMA, que editou a Resolução $n$. $302 / 2002^{40}$.

Cabe destacar que a citada resolução era criticada severamente por boa parte da doutrina ${ }^{41}$, em razão de estabelecer limites à propriedade não previstos em lei, violando-se, dessa forma, a Constituição Federal.

Nos termos da controversa Resolução 302/2002, assim definiam-se as APPs de reservatórios destinados à produção de energia:

\footnotetext{
39 MACHADO, Paulo Afonso Leme. Direito Ambiental Brasileiro. São Paulo: Malheiros, 2012, p. 863. No mesmo sentido, Édis Milaré, com base no Código Florestal de 1965, aduz que "Em particular a inserção da expressão "coberta ou não por vegetação nativa", denota a intenção do legislador de dar proteção não exclusivamente às florestas e demais formas de vegetação natural, mas aos locais e às formações geográficas em que tais áreas estão inseridas funcionalmente, ou seja, na ação recíproca e sinérgica entre a cobertura vegetal e sua preservação e a manutenção das características ecológicas do domínio em que ela ocorre" (MILARÉ, Edis. Direito do Ambiente. São Paulo: Revista dos Tribunais, 2011, p. 953).

40 Lei 4.771/1965, - artigo 40, § 6o, após a redação conferida pela Medida Provisória 2.166-67/2001 ao revogado diploma. Antes de 2002, a questão era tratada pela Resolução n. 04/1985, do mesmo conselho. Vale destacar que, antes de 1985, já havia usinas construídas e em operação.

${ }^{41}$ Podemos citar, dentre outros, Paulo Afonso Leme Machado (Direito Ambiental Brasileiro. São Paulo: Malheiros, 2011, p. 832) e Maria Luiza Machado Granziera (Direito Ambiental. São Paulo: Atlas, 2011, p. 453).
} 
Art 3 Constitui Área de Preservação Permanente a área com largura mínima, em projeção horizontal, no entorno dos reservatórios artificiais, medida a partir do nível máximo normal de:

trinta metros para os reservatórios artificiais situados em áreas urbanas consolidadas e cem metros para áreas rurais;

II - quinze metros, no mínimo, para os reservatórios artificiais de geração de energia elétrica com até dez hectares, sem prejuízo da compensação ambiental.

III - quinze metros, no mínimo, para reservatórios artificiais não utilizados em abastecimento público ou geração de energia elétrica, com até vinte hectares de superfície e localizados em área rural.

$\S 1$ 응 Os limites da Área de Preservação Permanente, previstos no inciso I, poderão ser ampliados ou reduzidos, observando-se o patamar mínimo de trinta metros, conforme estabelecido no licenciamento ambiental e no plano de recursos hídricos da bacia onde o reservatório se insere, se houver.

$\S 2$ O Os limites da Área de Preservação Permanente, previstos no inciso II, somente poderão ser ampliados, conforme estabelecido no licenciamento ambiental, e, quando houver, de acordo com o plano de recursos hídricos da bacia onde o reservatório se insere.

$\S 3$ ㅇ A redução do limite da Área de Preservação Permanente, prevista no $\S 1$ o deste artigo não se aplica às áreas de ocorrência original da floresta ombrófila densa - porção amazônica, inclusive os cerradões e aos reservatórios artificiais utilizados para fins de abastecimento público. [...]

$\S 60$ Não se aplicam as disposições deste artigo às acumulações artificiais de água, inferiores a cinco hectares de superfície, desde que não resultantes do barramento ou represamento de cursos d’água e não localizadas em Área de Preservação Permanente, à exceção daquelas destinadas ao abastecimento público ${ }^{42}$. (Grifamos)

Percebe-se que o CONAMA fixava somente metragens mínimas e que apresentava critérios e limites para o aumento e a redução dessas áreas ${ }^{43}$. Esse regime foi revogado, ao que tudo indica, pelo atual marco florestal.

${ }^{42}$ BRASIL. Conselho Nacional do Meio Ambiente (CONAMA). Resolução n. 302, de 20 de março de 2002. Dispõe sobre os parâmetros, definições e limites de Áreas de Preservação Permanente de reservatórios artificiais e o regime de uso do entorno. Brasília: 2002.

${ }^{43}$ Idem. Ibidem, art. 30, § 40: "a ampliação ou redução do limite das Áreas de Preservação Permanente, a que se refere o $\S 10$, deverá ser estabelecida considerando, no mínimo, os seguintes critérios: 1 características ambientais da bacia hidrográfica; II - geologia, geomorfologia, hidrogeologia e fisiografia da bacia hidrográfica; III - tipologia vegetal; IV - representatividade ecológica da área no bioma presente dentro da bacia hidrográfica em que está inserido, notadamente a existência de espécie ameaçada de extinção e a importância da área como corredor de biodiversidade; V - finalidade do uso da água; VI - uso e ocupação do solo no entorno; VII - o impacto ambiental causado pela implantação do reservatório e no entorno da Área de Preservação Permanente até a faixa de cem metros. § 50 Na hipótese de redução, a ocupação urbana, mesmo com parcelamento do solo através de loteamento ou subdivisão em partes ideais, dentre outros 
Atualmente, nos casos previstos no caput do artigo 50 da Lei 12.651/2012, "é obrigatória a aquisição, desapropriação ou instituição de servidão administrativa pelo empreendedor das Áreas de Preservação Permanente criadas em seu entorno, conforme estabelecido no licenciamento ambiental, observando-se a faixa mínima de 30 (trinta) metros e máxima de 100 (cem) metros em área rural, e a faixa mínima de 15 (quinze) metros e máxima de 30 (trinta) metros em área urbana"44.

Dentre os instrumentos possíveis de serem utilizados para a garantia das APPs, o código atual inseriu a servidão administrativa, ampliando o leque e opções do empreendedor - antes limitado à desapropriação e à aquisição dos terrenos.

Para Júlio Cezar Lima Brandão, "a lei confere à administração pública uma liberdade muito grande para definir a largura do entorno, a depender dos estudos ambientais a serem analisados pelo órgão ambiental competente" ${ }^{145}$.

Já Priscila Santos Artigas defende o novo regime jurídico, comparando-o com o anterior, no qual ocorria a limitação do direito de propriedade a partir de um ato normativo do CONAMA, já que a Lei 4.771/1965 não fixava os limites das APPs em questão ${ }^{46}$.

O § 1ำ do mesmo artigo 50 autoriza o uso de até 10\% (dez por cento) do total da APP, desde que seja aprovado, dentro do licenciamento, um "Plano Ambiental de Conservação e Uso do Entorno do Reservatório"47, observadas as diretrizes técnicas expedidas pelo órgão ou entidade responsável pela avaliação e expedição das licenças. Esse plano deve ser aprovado antes do início da operação do empreendimento, não impedindo, entretanto, a expedição da licença de instalação, conforme o § 2ำ do citado artigo.

Nos autos da Ação Direta de Inconstitucionalidade n. 4903, a Procuradoria Geral da República requer que o dispositivo acima citado seja interpretado conforme a Constituição, para que não estabeleça o texto da Lei 12.651 metragens mínimas ou máximas, resgatando-se, assim, o papel do CONAMA na definição das metragens mínimas observáveis ${ }^{48}$. Aguarda a demanda citada a decisão do Supremo Tribunal Federal.

mecanismos, não poderá exceder a dez por cento dessa área, ressalvadas as benfeitorias existentes na área urbana consolidada, à época da solicitação da licença prévia ambiental".

${ }^{44}$ BRASIL. Ob. Cit.

${ }^{45}$ BRANDÃO, Júlio Cezar Lima. Novo Código Florestal Brasileiro: anotações à Lei 12.651/2012. Curitiba: Juruá, 2012, p. 115.

${ }^{46}$ ARTIGAS, Priscila Santos. Comentários ao artigo 5o. In: In: MACHADO, Paulo Afonso Leme; MILARÉ, Édis (coord.) Novo Código Florestal: comentários à Lei 12.651, de 25 de maio de 2012, e à MEdProv 571, de 25 de maio de 2012. São Paulo: Editora Revista dos Tribunais, 2012, p. 154-161.

${ }^{47}$ Este plano já era exigido no regime jurídico florestal anterior, com base no artigo 40 da Res.n. 303 do CONAMA.

${ }^{48}$ BRASIL. Ação Direta de Inconstitucionalidade 4903. Petição Inicial, p. 40. 
Ao que tudo indica, o estabelecimento de limites máximos para as faixas de APP limita a discricionariedade técnica do órgão ambiental e o poder de polícia administrativa, exercido de forma preventiva no licenciamento, já que, demonstrada a necessidade de uma faixa maior de proteção, esta não será exigível, por ultrapassar os limites positivados ${ }^{49}$.

Tal poderá não apenas fragilizar o equilíbrio ambiental nos locais que venham a abrigar esses empreendimentos, como também representar riscos ( $p$. ex. de perdas materiais) para aqueles que venham a ocupar o entorno dos mesmos para fins de moradia ou exercício de atividades econômicas.

\section{CONCLUSÕES}

Como visto, o setor de produção de energia a partir do aproveitamento de potenciais hidrelétricos enfrenta o risco de sérios prejuízos em razão da simples e dura escassez de água. Essa crise, que se reflete também no abastecimento de água potável, não pode ser absurdamente atribuída ao regime de chuvas, mas sim a uma série de questões como as falhas de gestão, os usos intensivos por setores que exportam água virtual e o desrespeito do ciclo natural deste insumo vital.

Curiosamente, o atual marco legal florestal, a Lei 12.651/2012, fragiliza a proteção das áreas de preservação permanente, cuja função ecológica, em boa parte dos casos, está diretamente ligada manutenção da disponibilidade, quantitativa e qualitativa, dos recursos hídricos.

No caso das hidroelétricas, nos parece que a fixação de limites máximos para a definição das áreas de preservação permanente dentro do licenciamento ambiental retira a vantagem desse modelo, que seria a de poder conferir a proteção mais adequada, avaliando-se cada caso. Ocorre que a legislação atual impossibilita isso quando traz limites tais máximos. Isso porque, possivelmente, os limites máximos estabelecidos não atenderão as necessidades de áreas de preservação permanente em todos os reservatórios.

Outra saída talvez uma saída seria a adoção de outro modelo que, com base em estudos técnicos, estabeleça um escalonamento complexo das áreas de preservação permanente em

\footnotetext{
${ }^{49}$ Da mesma forma se posiciona Maria Luiza Machado Granziera (Ob. cit., p. 468).
} 
função do tamanho dos reservatórios, a exemplo do que ocorre com as faixas marginais de proteção - desde que devidamente fundamentado e desejável sob o ponto de vista técnico. Esse outro modelo, aparentemente, geraria uma maior segurança jurídica para os empreendimentos, pois diminuiria a discricionariedade técnica do órgão ou entidade responsável pela análise e expedição das licenças ambientais.

Manter áreas de preservação permanente no entorno de reservatórios, embora seja visto como custo, parece contribuir para a vida útil do próprio empreendimento, na medida em que favorece o ciclo de renovação da água e desfavorece processos erosivos prejudiciais para o acúmulo de água.

Enfrentar os desafios hídricos e energéticos exigirá do Estado brasileiro a adoção de uma série de medidas, que não se resumiriam apenas ao que fora dito acima.

Não obstante, demonstra-se de vital importância a proteção efetiva das áreas de preservação permanente - incluídas aqui as matas ciliares de cursos d'água, o entorno de nascentes e outras áreas de recarga, tendo-se por pressuposto irrenunciável o desempenho pleno de suas funções ecológicas, o que não parece estar contemplado satisfatoriamente na Lei 12.651/2012. Do contrário, teremos que nos acostumar à escassez de recursos hídricos e aos conflitos que surgirão por água e energia.

\section{REFERÊNCIAS}

AGÊNCIA NACIONAL DE ÁGUA (ANA). Reserva Técnica começa a ser usada no Santa Branca, no Paraíba do Sul. Disponível em www2.ana.gov.br/Paginas/imprensa/noticia.aspx?id_noticia=12650. Acesso em 28 jan. 2015.

Reservatório Paraíbuna, no Paraíba do Sul, começa a usar reserva técnica. Disponível em http://www2.ana.gov.br/Paginas/imprensa/noticia.aspx?id_noticia=12649. Acesso em 28 jan. 2015.

ARTIGAS, Priscila Santos. Comentários ao artigo 5o. In: In: MACHADO, Paulo Afonso Leme; MILARÉ, Édis (coord.). Novo Código Florestal: comentários à Lei 12.651, de 25 de maio de 2012, e à MEdProv 571, de 25 de maio de 2012. São Paulo: Editora Revista dos Tribunais, 2012, p. 154-161.

AVZARADEL, Pedro Curvello Saavedra. Das Florestas Protetoras às Áreas de Preservação Permanente: considerações sobre os retrocessos na legislação florestal atual. In: XXII Encontro Nacional do CONPEDI / UNICURITIBA, 2013, Curitiba. Direito Ambiental II XXII Encontro Nacional do CONPEDI/UNICURITIBA. Florianópolis: FUNJAB, 2013. p. 164-184.

BANCO MUNDIAL. Licenciamento Ambiental de Empreendimentos Hidrelétricos no Brasil: uma Contribuição para o Debate. Volume II: relatório principal. Brasília: 2008.

BOTKIN, Daniel B; KELLER, Eduard A. Ciência ambiental: terra, um planeta vivo. Rio de Janeiro: LTC, 2011. 
BRANDÃO, Júlio Cezar Lima. Novo Código Florestal Brasileiro: anotações à Lei 12.651/2012. Curitiba: Juruá, 2012.

BRASIL. Conselho Nacional do Meio Ambiente. Resolução n. 1, de 23 de Janeiro de 1986. Dispõe sobre critérios básicos e diretrizes gerais para a avaliação de impacto ambiental. Brasília: 1986. Conselho Nacional do Meio Ambiente. Resolução n. 6, de 16 de setembro de 1987. Dispõe sobre o licenciamento ambiental de obras do setor de geração de energia elétrica. Brasília: 1987.

Constituição da República Federativa do Brasil, de 5 de outubro de 1988. Brasília: 1988.

Lei 9.427, de 24 de setembro de 1996. Institui a Agência Nacional de Energia Elétrica - ANEEL, disciplina o regime das concessões de serviços públicos de energia elétrica e dá outras providências. Brasília: 1996.

Lei 9.433, de 8 de janeiro de 1997. Institui a Política Nacional de Recursos Hídricos, cria o Sistema Nacional de Gerenciamento de Recursos Hídricos. Brasília: 1997.

Medida Provisória n. 1.956-50, de 26 de maio de 2000. Altera os arts. 1ㅇ, 4으, 14, 16 e 44, e acresce dispositivos à Lei no 4.771, de 15 de setembro de 1965, que institui o Código Florestal, bem como altera o art. 10 da Lei no 9.393, de 19 de dezembro de 1996, que dispõe sobre o Imposto sobre a Propriedade Territorial Rural - ITR, e dá outras providências. Brasília: 2000.

Conselho Nacional do Meio Ambiente. Resolução n. 279, de 27 de junho de 2001. Estabelece procedimentos para o licenciamento ambiental simplificado de empreendimentos elétricos com pequeno potencial de impacto ambiental. Brasília: 2001.

Conselho Nacional do Meio Ambiente (CONAMA). Resolução n. 302, de 20 de março de 2002. Dispõe sobre os parâmetros, definições e limites de Áreas de Preservação Permanente de reservatórios artificiais e o regime de uso do entorno. Brasília: 2002.

Ministério da Ciência e Tecnologia. Primeiro Inventário Brasileiro de Emissões Antrópicas de Gases de Efeito Estufa. Relatórios de referência: emissões de dióxido de carbono e de metano pelos reservatórios hidrelétricos brasileiros. Brasília: 2006.

Ministério das Mimas e Energia. Matriz Energética Nacional 2030. Brasília: MME/EPE, 2007.

Lei Complementar 140, de 8 de dezembro de 2011. Regulamenta o parágrafo único do artigo 23 da Constituição Federal. Brasília: 2011.

Lei n. 12.651, de 25 de maio de 2012. Dispõe sobre a proteção da vegetação nativa; altera as Leis nos 6.938, de 31 de agosto de 1981, 9.393, de 19 de dezembro de 1996, e 11.428, de 22 de dezembro de 2006; revoga as Leis nos 4.771, de 15 de setembro de 1965, e 7.754, de 14 de abril de 1989, e a Medida Provisória $n^{\circ}$ 2.166-67, de 24 de agosto de 2001; e dá outras providências. Brasília: 2012.

Ministério das Cidades. Secretaria Nacional de Saneamento Ambiental. Sistema Nacional de Informações sobre Saneamento: Diagnóstico dos Serviços de Água e Esgotos - 2013. - Brasília: MCIDADES.SNSA, 2014.

CARLI, Ana Alice de. A água e seus instrumentos de efetividade. Campinas: Millennium Editora, 2013.

CARMO, Roberto Luiz do; Et. Al. Água virtual, escassez e gestão: O Brasil como grande "exportador" de água. In: Ambiente \& Sociedade. Campinas v. X, n. 2, p. 83-96, jul.-dez. 2007.

ESTADO DO RIO DE JANEIRO. Lei 3.239, de 2 de agosto de 1997. Institui a Política Estadual de Recursos Hídricos, cria o Sistema Estadual de Gerenciamento de Recursos Hídricos. Rio de Janeiro: 1999. 
FEARNSIDE, Philip M.; PUEYO, Salvador. Emissões de gases de efeito estufa em reservatórios de hidroelétricas: implicações de uma lei de potencia. Oecologia Australis, 2011.

GRANZIERA, Maria Luiza Machado. Direito Ambiental. São Paulo: Atlas, 2011. HIROTA, Marcia. Por que desmatar $79 \%$ da área de mananciais secou São Paulo. Disponível em http://www.sosma.org.br/101149/por-que-desmatar-79-da-area-de-mananciais-secou-saopaulo/\#sthash.jOsvXhWt.dpuf. Acesso em 28 jan. 2015.

INTERNATIONAL RENEWABLE ENERGY AGENCY (IRENA). Renewable Energy Technologies: Cost analysis series. Volume 1. Power Sector. Issue 3/5, Hydropower. Abu Dhabi: 2012.

IPCC. Mudança do Clima 2007: A Base das Ciências Físicas Contribuição do Grupo de Trabalho I ao Quarto Relatório de Avaliação do Painel Intergovernamental sobre Mudança do Clima. Genebra, 2007.

NITAHAR, Akemi. Nível baixo dos reservatórios leva segunda hidrelétrica a parar. Disponível em http://agenciabrasil.ebc.com.br/geral/noticia/2015-01/nivel-baixo-dos-reservatorios-leva-segundahidreletrica-parar. Acesso em 26 jan. 2015.

MACHADO, Paulo Afonso Leme. Direito Ambiental Brasileiro. São Paulo: Malheiros, 2012.

MILARÉ, Edis. Direito do Ambiente. São Paulo: Revista dos Tribunais, 2011.

MEKONNEN, M.M; HOEKSTRA, A.Y. (2011) National water footprint accounts: the green, blue and grey water footprint of production and consumption, Value of Water Research Report Series n. 50. Delft (Netherlands): UNESCO-IHE, 2011.

Trabalho enviado em 22 de março de 2015.

Aceito em 27 de junho de 2015. 